$\frac{201 / \gamma^{8}-11}{1 / 2}$

Informal Report

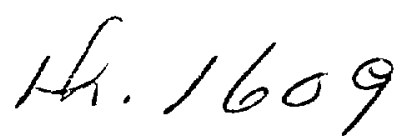

UC-32

Issued: October 1977

\title{
DENBIG and DARN. \\ Codes for the Reduction of \\ Digital Pinex Data
}

\author{
Louis M. Beyer*
}

"LASL Consultant: Murray State University, Department of Physics and Computer Science, Murray, KY 42071.
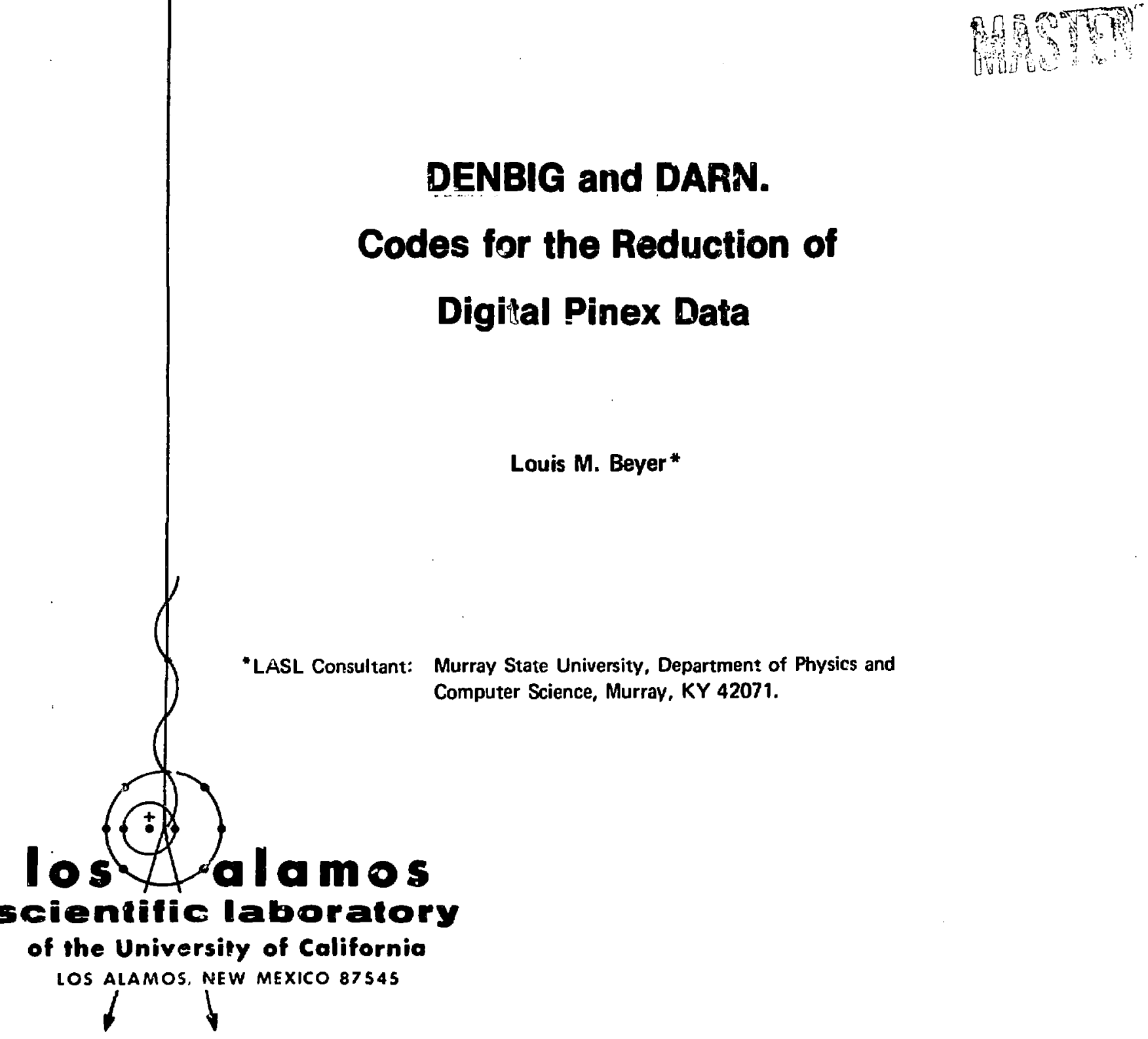

An Alfirmative Action / Equal Opportunity Employer 


\title{
DENBIG AND DARN. CODES FOR THE REDUCTION OF DIGITAL PINEX DATA
}

\author{
by
}

Louis M. Beyer

\begin{abstract}
Code DE $\sqrt{ }$ BIG was written to reduce the digital pinex data received fron: the Neveda Teat Site (NTS) and Transient Reactor Test Facility (TREAT) experiments. Output modes are density plots, contour plots, splatter plots, equivalent radius calculations, line cuts, and reduced data in matrix form. Provisions are included to incorporate subtraction of dryrun data, tranofer function corrections, and pinhole absorption corrections. Code DARN processes pinex data in which electromagnetic pulse shifts have aliminated sync tips or caused unsaturated amplitude variations. These induced problems are eliminated by clamping the data, point by point, to dryrun data. The DARN output modes are a subset of those of DIBNBIG. The data frame established by DARN can be filed for subsequent input to DENBIG. Program descriptions and operating instructions are discussad.
\end{abstract}

\footnotetext{
This report ats prepared as an eccount of work vponsored by the United States Covernment. Neither the United States not the Unitat States Deparment of

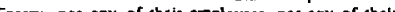
Energ. nor any of dhis en contractors, subcontractors, of tretr employees, makes bny wartenty, express or tmplied, of asumes any legal lisbillty or responsibility for the accuracy, completeness or usefulness of any informution, appiralus, pradict or process discloced, or represents that is uxe would not infriage privately owned rights.
} 


\section{DENBIG, A CODE FOR THE REDUCTION OF DIGITAL PINEX DATA}

\section{INTRODUCTION}

Computer code DENSITY ${ }^{1}$ has for several years been the primary analysis program of digitally recorded Nevada Test Site (NTS) pinex data. Some minor changes through the years, plus new features and modified operating procedures recently incorporated, merited an updated report on the code. Pari $I$ of this report describes the code in its updated form, now called DENBIC.

Experience with problems encounteret in pinex data recording suggested that slightly different analysis procedures could be used to extract good run data by incorporating more dependence on dryrun data. An alternate version of DENSITY, code DARN, written specifically to analyze data with electromagnetic pulıe shifts, is described in Part II of this report.

The pinex data recorded digitally at NTS is preprocessed into consecutive amplitude values of segments of TV lines. Each amplitude corresponds to the intensity within a 50-ns sweep interval of the camera. Theiefore, a $30-\mu$ s sweep time translates into about 600 data points per line. The camera is then clamped to dc zero, producing several points at that level, followed by a negatively biased horizontal synchronization tip (HST) of about 2.5- $\mu$ S duration before another line sweep begins. Figure 1 demonstrates a segment of the input data, showing an HST, data line, and the beginning of the next HST. It is the task of the code to decompose at least 155000 consecutive amplitude values into about 240 lines of 600 points each and to transform the resulting data into useful results. The code is dimensioned to handle line lengths as long as $\mathbf{1 5 0 0}$ points, such as those encountered when $33-\mathrm{ms}$ cameras are used. ${ }^{2}$

1. W. M. Sanders, Los Alamos Scientific Laboratory internal report (1972).

2. G. J. Berzins and K. S. Han, "Pinhole Imaging of a Test Fuel Element at TREAT." To be published in Nucl. Sci. Eng.

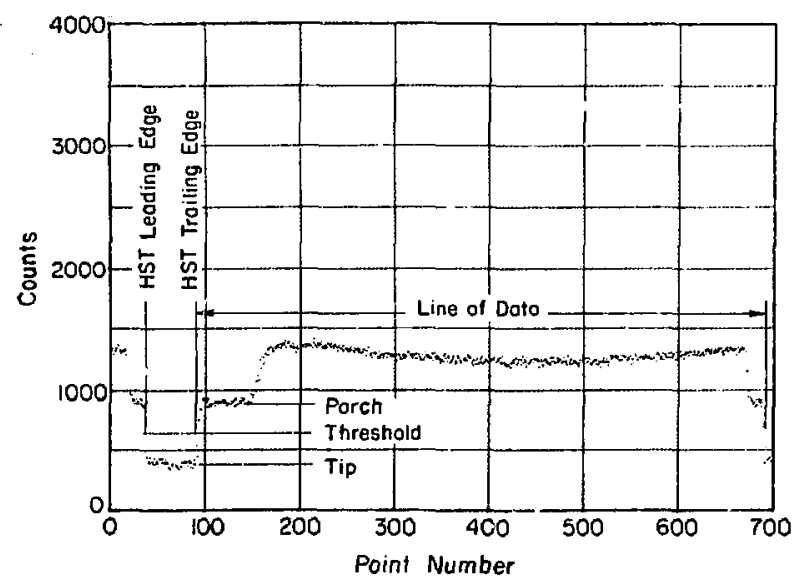

Fig. 1.

An arbitrary segment of the data-plotted am. plitude us point number. Demonstrated are the definitions tip, threshold and porch levels, leading and trailing edges of the HST, and the extent of one line of TV data.

\section{REDUCTION OF THE DATA INTO A SQUARE ARRAY}

\section{A. Line Clamping}

A number is entered by the user with a value halfway between the bottom of the HST (tip value) and the dc zero level (porch value). This is the initial threshold value. The code then searches data until it finds a data point below this threshold. This position is taken as the beginning of $t^{2}$ a first HST. It then searches forward until a data point exceeds the threshold. This position is taken as the end of the first HST. The HST data are then severely srooothed by a seven-point, five-times-repeated srnoothing function. An exact position $( \pm 0.01$ data point) is then salculated where the leading edge of the HST crosses the threshold. This value (XSLIM) 
ties the data for the TV line, which follows the trailing edge of the HST, to the HST leading edge crossing of the threshold. Average values of the tip and the following porch are then averaged for a new threshold value. The above definitions are depicted in Fig. 1 .

The search for ciata of the first TV line then proceeds by picking up at the last poin $\mathrm{\imath}$ searched (the point of the HST"s trailing edge) and by searching forward until the threshold again exceeds the data, that is, until the next HST is encountered. The number of data vaiues in the line, the line number, XSLIM, and the data values are filed on tape.

The code has now encountered the second HST, enabling the above steps to be repeated on succeeding data. During the process of analyzing each point, user-entered variables cause checks on valid HST (too short or too long), valid lines (too short or too long), and background subtraction (subtract porch value point by point, or no subtraction). In addition, some electronically induced problems are manipulated, as shown in Fig. $\approx$. The HST shown here has a positive ringing on the porch, causing an excessive porch and threshold calculation that, in turn, misplaces the next HST. The code checks new porch calculations against the old value and steps up the porch position for repeated new calculations until new and old agree to within $10 \%$, or it uses the old value. Various other checks are built into the code.

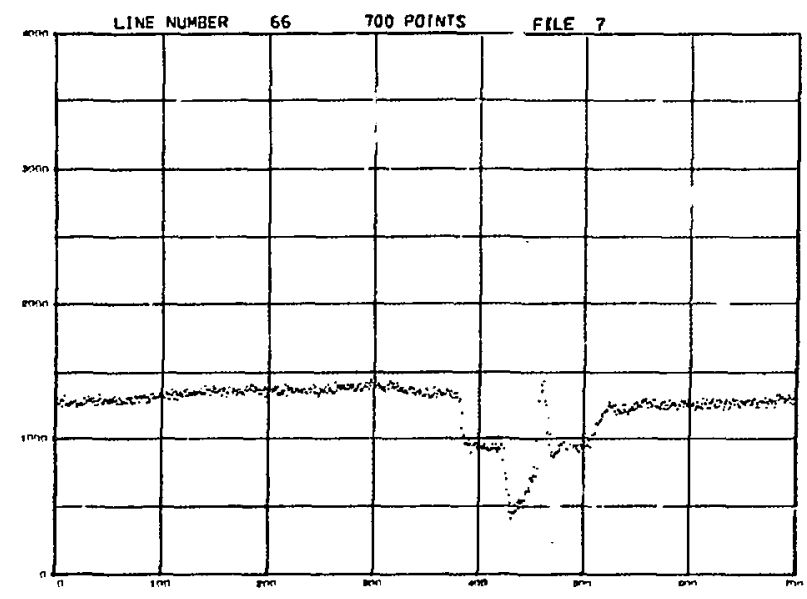

Fig. 2.

The HST has an induced ringing on the porch that the code detects and skips in porch calculations.
The process of analyzing an HST, finding and storing the succeeding line, and repeating is continued until a user-entered line limit is reached.

\section{B. Matrix Conversion}

The data are now stored as about 240 rows of about 600 points each row. The number of points in each line is not necessarily the same, nor is the displacement, XSLIM, from the leading edge of each HST a constant. An interpolation routine is next ap.. plied to align the starting point of each line, cordense the line length to 500 points, and finally expand the number of lines to 500 . In addition, usirentered parameters can redefine beginning row and column numbers, as well as produce magnificacion in the $\mathrm{x}$ and $\mathrm{y}$ directions to square the frame of interpolated data.

Considerable smoothing of the data occurs during the interpolation process. The smoothing function is user entered in terms of the number of points used in the smooth and weights. For a seven-point smooth, four weights $S_{1}-S_{4}$ are entered. A smoothed value $Y_{S_{J}}$ is then calculated from data values $Y_{J-8}-Y_{J+8}$.

$$
\begin{aligned}
& Y S_{J}=S_{1}\left(Y_{J-3}+Y_{J+3}\right)+S_{2}\left(Y_{J-2}+Y_{J+2}\right) \\
& +S_{3}\left(Y_{J-1}+Y_{J+1}\right)+S_{1} Y_{J}
\end{aligned}
$$

Ideally, the smoothing takes out high-frequency fluctuations in the data (noise) and leaves lowfrequency variations unaltered. Figure 3 shows the smoothing factor as a function of $\mathrm{x}$ for the function $\cos (3 \pi x)$ with the indicated values for the smoothing coefficients $S_{\mathrm{J}}$. This curve may be interpreted in terms of a frequency dependence by associating the 50-ns time interval between successive points with $x$. If seven successive points above a background constitute $1 / 8$ wavelength of an oscillation, the fourth would be smoothed to $98 \%$ of its original value, and the frequency would be $0.35 \mathrm{MHz}$. Conversely, if seven data points constitute a full oscillation, the midpoint is smoothed to $20 \%$ of its original value and the frequency would be $2.86 \mathrm{MHz}$. The $50 \%$ smoothing point of coefficients given corresponds to a frequency of about $2.5 \mathrm{MHz}$.

$T_{i}$ : code also has the option of next processing the frame of dryrun data in an analogous procedure 


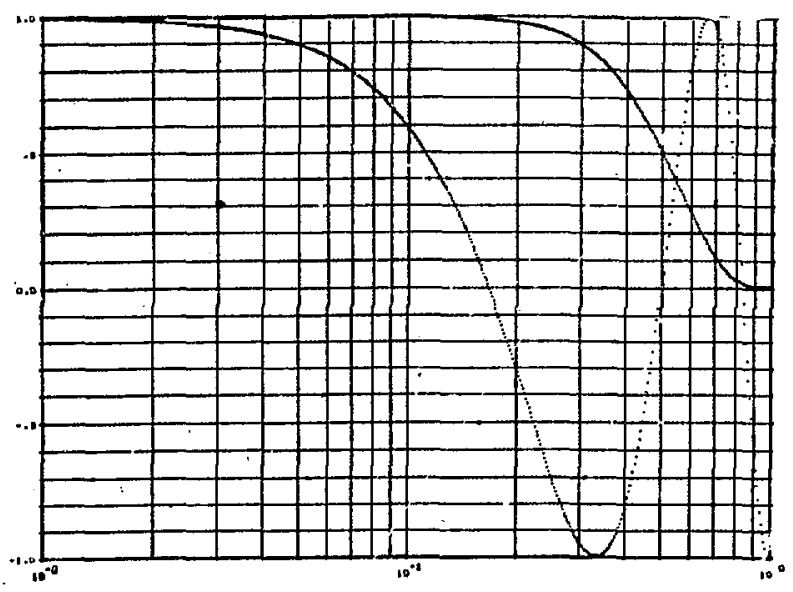

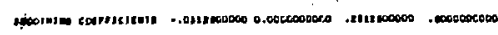

Fig. 3.

A plot of $\cos 3 \pi x$ and the smoothing magnitide us $x$.

so that this background data can be subtracted, thus eliminating variations in the camera background across each line. The camera variation as a function of position is demonstrated in Fig. 1, which is almost entirely background data. This is an important data correction because each camera variation may be different.

\section{DATA CORRECTIONS AND PLOTS}

\section{A. Transfer Function Application}

The data on amplitude output vs light input for each camera is known as the transfer function. These data are obtained at NTS directly by measuring the ou'put voltage of the camera as a function of calibration light intensity, and from the dryrun frames is the counts above background for the line of the frame through the center of the calibration lights. After normalizing voltage to counts, the code accepts data on counts vs intensity and constructs a mathematical expression for the transfer following subtraction of the dryrun data, although it can be applied to the shot frame directly if no dryrun subtraction is exercised. Data distortion will occur near the ends of the lines in this latter case unless the camera line is extremely flat. In addition, transfer data must be total counts above the porch value if no dryrun subtraction is applied.

The quality of the data is greatly enhanced by proper dryrun subtraction and transfer function appilcation, as shown in Figs. 4-6. Figure 4 is a shot frame with no transfer function corrections nor background subtraction. Figure 5 shows the results of separately applying the transfer function (relative to porch values) to the shot and dryrun frames successively, followed by subtraction. Figure 6 shows the results of subtracting the frame of dryrun data from the shot frame, followed by transfer function (relative to zero background) application. The most prominent improvement in the data is the proper correction in low amplitude regions of the frame due to proper subtraction in regions where camera lines are not flat.

The data in the 500-by-500 point matrix, after all background and transfer function corrections, are the final internal representation. These data can be saved on file in this form for later input to the sume code, can be printed (all or a specified part), or can be plotted in several representations.

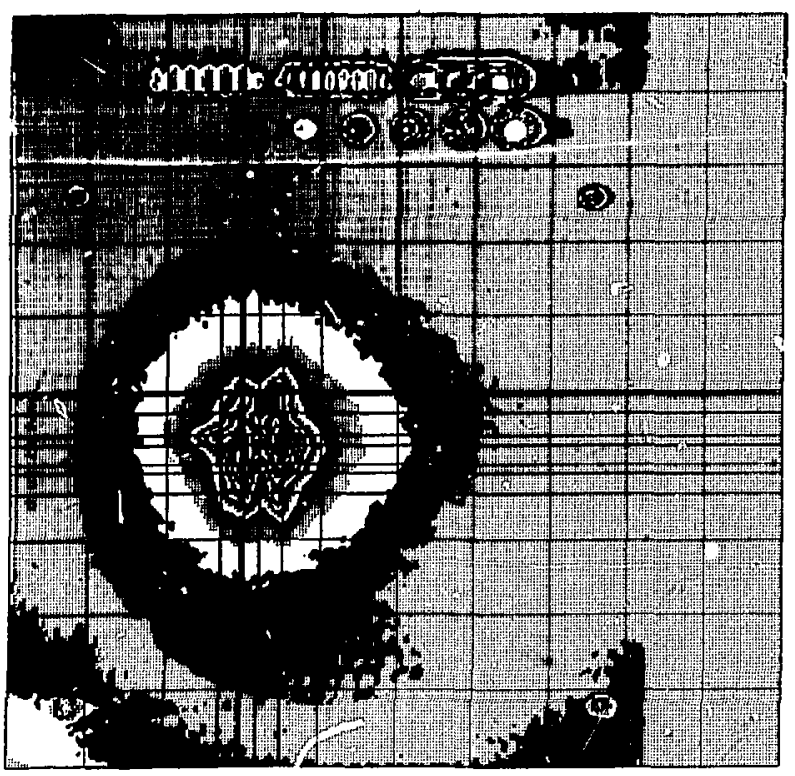

Fig. 4.

A density plot of shot data with calibration lights near the top, with no background or transfer function correction. 


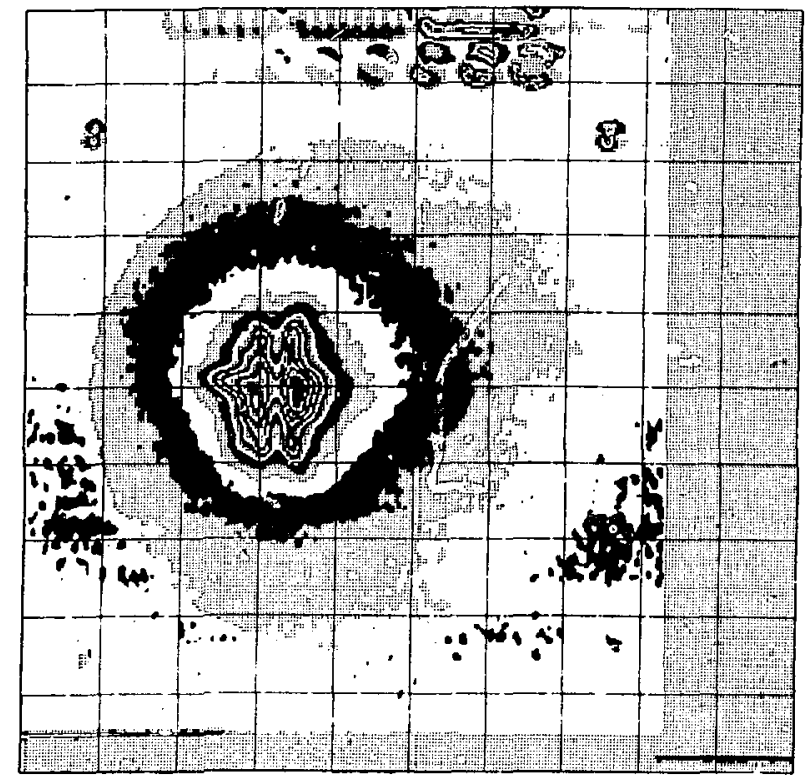

Fig. 5.

A density plot of the same shot as Fig. 4 with the transfer function applied separately to shot and background frames followed by background subtraction.

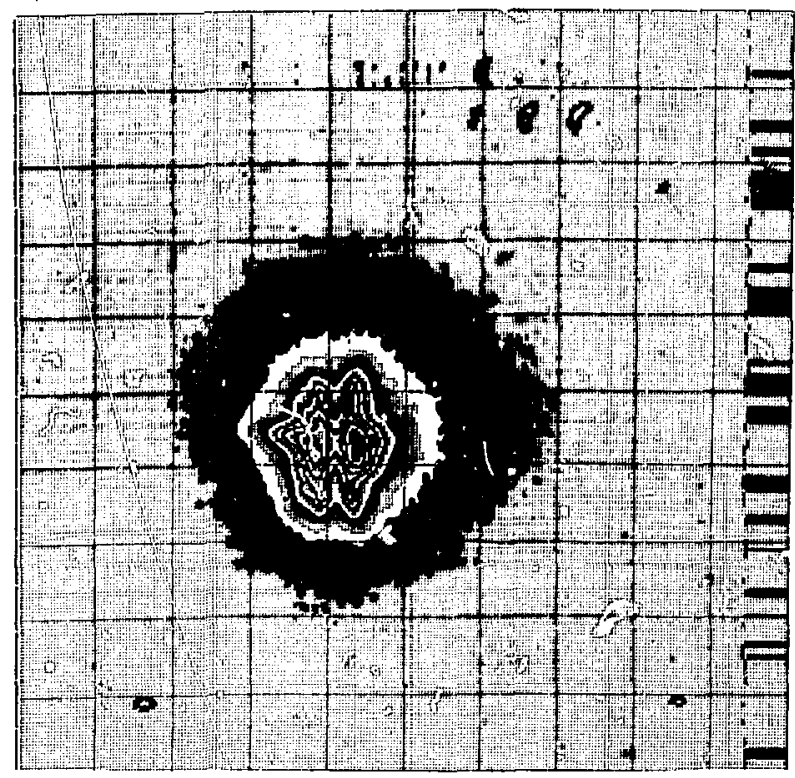

Fig. 6.

$A$ dansity plot of the same shot as Fig. 4 with the background frame subtracted from the shot frame followed by a transfer function correction.

\section{B. Data Representation by Plots}

The data in matrix form can be output to film plots of several forms: density plots, contour plots, splatter plots, and line plots (a cut across any part of the matrix). The highest data point (MAX) is usually normalized to 100 in plot routines.

1. Density $y_{2}$ Plots. The density plot represents various regions of the matrix with the same range of amplitude with a particular degree of darkening on film. The usual procedure is to use three levels of plotting density: black, halftone, and white, with all points in the matrix 0.95 MAX-1.00 MAX black, 0.90 MAX-0.95 MAX halftone, 0.85 MAX-0.90 MAX white, 0.80-MAX-0.85 MAX black, etc. Therefore, the plot progresses from high intensity to low in the order black, halftone, white, black, halftone, white, etc. Successive areas of equal shading are separated by $15 \%$ MAX. The percentage range and number of levels (that is, 1/3 tone, $1 / 4$ tone, etc., also options) are user chosen. Figures 4-6 are density plots.

2. Contour Plois. Contour plets are generated on film by connecting adjacent points of the matrix in the $x$ direction, where one of the points has the contour value specified. The process is repeated in the $y$ direction. The results are almost continuous lines of equal intensity (value is user specified), but not overly satisfying. Figure 7 is a contour plot of the matrix of Fig. 6.

3. Splatter Plots. Splatter plots are a two-level representation of the data. All points within a specified intensity range are exposed, whereas those outside that range are unexposed. Figures 8 and 9 are splatter plots of two intensity levels of the same data as Fig. 6.

4. Line Plots. A line plot of the intensity variation across the trame in any lirection can be obtained by specifying the start.ng and ending row and column numbers. Figure 10 is a line plot taken horizontally across the middle of the data of Fig. 6 . Up to 20 line plots can be generated in execution of the code. A density plot generated in the same run will have numbered lines superimposed upon it showing the cut taken for each line plot. 


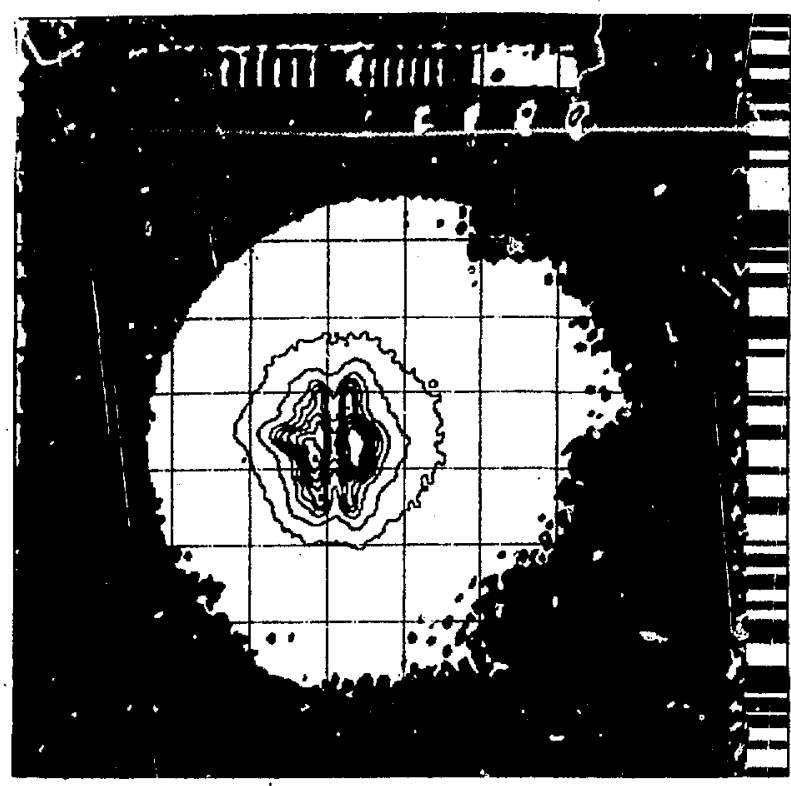

Fig. 7.

A contour plot of the same data as Fig. 6.

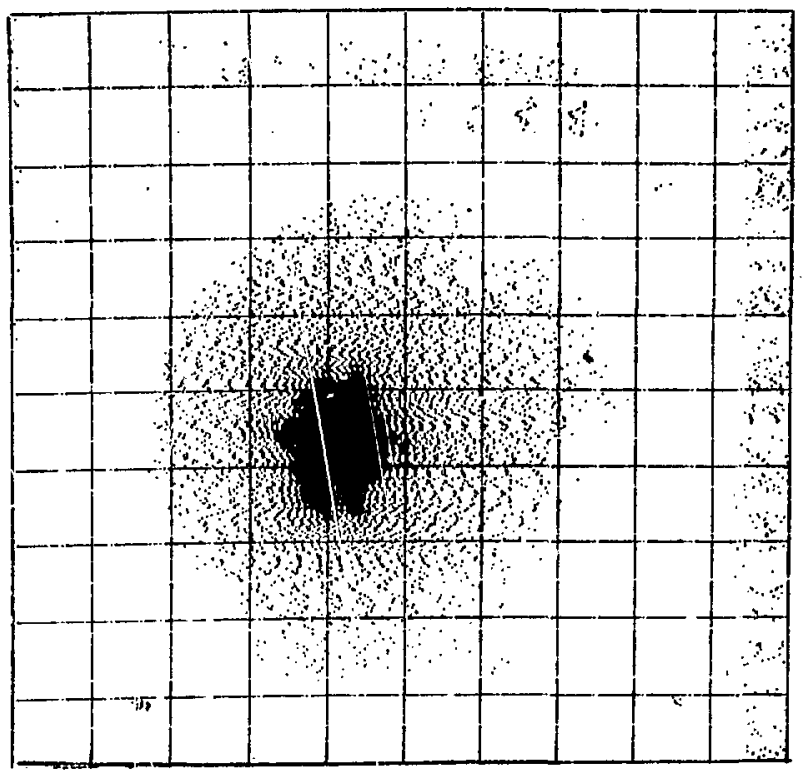

Fig. 8.

A splatter plot of the same doia as Fig. 6, where all points in the matrix with amplitude 0 - $100 \%$ of the maximum are black.

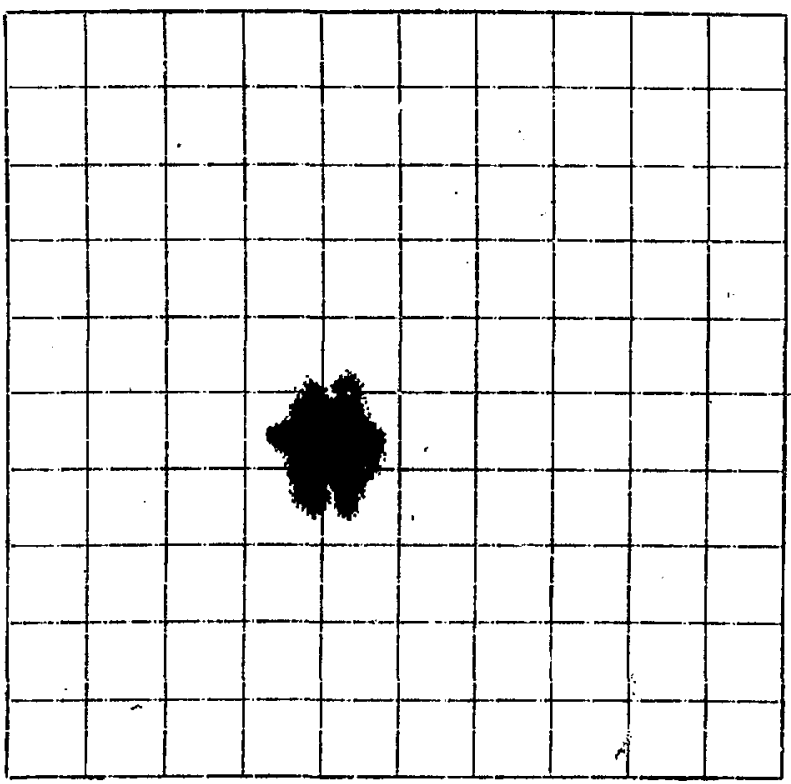

Fig. 9.

A splatter plot of the same data as Fig. 6, where all points in the matris with amplitude $25-100 \%$ of the maximum are black.

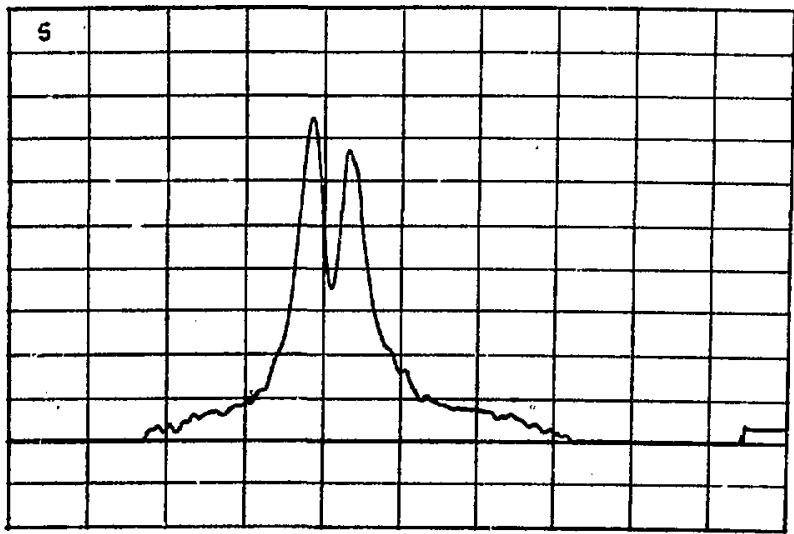

Fig. 10.

A line plot of row 306 from the data of Fig. 6. 
5. Miscellaneous Features. Output plots can be crosshatched with eny number of grid lines to facilitate positioning regions of interest. Ten divisions in each direction are usually convenitnt. Alternatively, a polar grid can be superim r osed on output plots by specifying the origir (row and column number) and radius of each circle desired.

An additional calculation provided by the program is the equivalent radius of circular contours within the matrix that enclose integrated amplitudes for a particular intensity range. Thus you can output the "center of gravity" of the matrix and the radius of a circle centered there that contains $5 \%$ of integrated amplitude, as well as $10 \%, 15 \%$, etc. Results are in numeric form rather than plot form.

Corrections for the pinhole transmission can also be applied to the matrix. The correction curve of transmission vs radius from the pintole code is input. The coordinates of the center of the frame can be those calculated by the above equivalent radius calculation. In this case, the results of the $5 \%, 25 \%$, $50 \%$, and $75 \%$ certers of the range integrated are sequentially taken. Optionally, the center can be an input parameter. In either case, the corrected matrix is then plotted by a density plot.

\section{OPERATING INSTRUCTIONS}

\section{A. Data Sets}

1. External Data Sets. Data received from NTS are usually unscrambled and stored in mass storage before executiog this code. If this is the case, FSET1 refers to shot data and FSET2 is the dryrun data.

If the code is to output the final 500 -by -500 matrix on tape, or if it is to use such data as input for further processing, FSET19 is used. Control cards must establish this file if it is to be saved.

2. Internal Data Sets. As lines of the TV data are clamped, they are written in sequence on FSET13 until interpoiated into a 500-by-500 array. If the shot frame is to have background subtracted, the shot matrix is saved on FSET18 until the dryrun data are clamped and interpolated.

No control cards are necessary to establish FSET13 and FSET18.

\section{B. General Operation Paranneters}

The data input to the program begins with input of keyvalues or keywords, in NA AELIS $\mathrm{i}$ format, described in Appendix A. If pararseters are omitted, they may be assigned defauit values. Some keywords or keyvalues initiate further input. That sequence, given in required order, is described in Appendix B with accompanying formats. Default vaiues have been extensively agsigned to greatly simplify input.

\section{SUMMARY}

This report describes the operation and input for code DENBIG, an update of the very successful code DENSITY. Changes incorporated into DENBIG include

a. An improved background subtraction operation,

b. Separate application of the transfer function to shct and dryrun data before subtraction,

c. A routine to accurately calculate porch and threshold values when "ringing" occurs on the porch,

d. Extended data capacity to handle line lengths of up to 1500 dats points, which may be encountered with TREAT ${ }^{2}$ data and new digitizers, and

e. Extensive tables of default values most commonly assigraed to input parameters.

It is arricipated that the updated description and simplified input will benefit present and future users of the code.

\section{ACKNOWLEDGMENT'S}

Several persons are responsible for this benefficial and enjoyable Visiting Staff Member appointment at LASL. K. S. Han and W. H. Roach were most helpful in all aspects of my visit. S. T. Donaldson and $B$. M. Wheat were patient, encouraging, and very helpful during struggles with an unfamiliar computer. I wish to especially thenk G. J. Berzins, who was instrumental in obtaining the appointment and so ably directed the problem. 
APPENDIX I-A

KEYWORD PARAMETERS

\begin{tabular}{|c|c|c|}
\hline Name & Values & Description \\
\hline TITLE = & $60 \mathrm{H}(60$ Characters $)$ & Any input title. \\
\hline TYPE = & $\begin{array}{l}\text { 10HFUNNGAMESb } \\
\text { 10HGMX11bDATA } \\
\text { 10HULTRAbDATA } \\
\text { 10HCARDbDATAb }\end{array}$ & $\begin{array}{l}\text { NTS data input (default value). } \\
\text { GMX11 data input. } \\
\text { Matrix input data. } \\
\text { Card data input. }\end{array}$ \\
\hline DERTV = & 10Hbbbbbbbbbb & $\begin{array}{l}\text { Interpolation using data values (default } \\
\text { value). }\end{array}$ \\
\hline & 10HGRADIENTS & Interpolation using derivatives. \\
\hline IFILE = & $\#$ & Shot data file number. \\
\hline IBFILE $=$ & \# & Dryrun data file number for subtraction. \\
\hline NHSMOO = & $\#$ & $\begin{array}{l}\text { Number of times to smooth horizontally } \\
\text { (default }=7 \text { ). }\end{array}$ \\
\hline NHSMOO $=$ & $\#$ & $\begin{array}{l}\text { Number of times to smooth verticaliy } \\
\text { (default = i). }\end{array}$ \\
\hline NOPTSM = & $\#$ & $\begin{array}{l}\text { Number of points to use in smoothing } \\
\text { (default }=7 \text { ). }\end{array}$ \\
\hline $\operatorname{SS}(1)=$ & \#,\#.\#,\# & (NOPTSM +1)/2 smoothing coefficients. \\
\hline NORM = & $\begin{array}{l}0 \\
1 \\
2\end{array}$ & $\begin{array}{l}\text { No plot normalization. } \\
\text { Percentage normalization for plots (default } \\
\text { value). } \\
\text { Plot maximum is input value. }\end{array}$ \\
\hline $\mathrm{ICBKG}=$ & $\begin{array}{l}0 \\
1\end{array}$ & $\begin{array}{l}\text { No constant background substraction (default } \\
\text { value). } \\
\text { Constant to subtract from matrix is input. }\end{array}$ \\
\hline NOLIN $=$ & $\#$ & $\begin{array}{l}\text { Number of vertical and horizontal lines } \\
\text { to superimpose on plots (default }=10 \text { ). }\end{array}$ \\
\hline IPRNT $=$ & $\begin{array}{l}0 \\
1\end{array}$ & $\begin{array}{l}\text { No line print of matrix (default value). } \\
\text { Input region of matrix to print. }\end{array}$ \\
\hline ITAPO = & $\begin{array}{l}0 \\
1\end{array}$ & $\begin{array}{l}\text { No output of matrix on FSET19 (default value). } \\
\text { Output matrix on FSET19. }\end{array}$ \\
\hline
\end{tabular}




\begin{tabular}{|c|c|c|}
\hline Name & Values & Description \\
\hline $\mathbf{I D}=$ & 2 & $\begin{array}{l}\text { (Used only if dryrun on FSET2 is to be } \\
\text { clamped and plotted as individual frame.) }\end{array}$ \\
\hline $\mathrm{NBR}=$ & $\#$ & $\begin{array}{l}\text { Number of lines to delete from matrix } \\
(\text { default }=0 \text { ). }\end{array}$ \\
\hline ITRANS = & 1 & $\begin{array}{l}\text { No transfer function correction (defuult } \\
\text { value). } \\
\text { Transfer function data to be input. }\end{array}$ \\
\hline NOLNS = & $\#$ & Number of line plots desired (defsult $=0$ ). \\
\hline NUM11 = & $\#$ & $\begin{array}{l}\text { Channel shift from HST end to porch } \\
\text { beginning. }\end{array}$ \\
\hline NUM21 = & \# & $\begin{array}{l}\text { Channel width of porch integration. } \\
\text { If } \#=0 \text {, no KLAMP subtraction. }\end{array}$ \\
\hline NUM31 = & $\#$ & Channel shift for HST integration. \\
\hline NUM41 = & $\#$ & Chunnel width of HST integration. \\
\hline NUM42 = & $\#$ & Minimum HST channel width. \\
\hline NUM43 = & $\#$ & Minimum VST channel width. \\
\hline NUM44 = & $\#$ & Maximum VST channel width. \\
\hline MINLIN = & $\#$ & Minimum channel width for line. \\
\hline LINTOT $=$ & $\#$ & Maximum channel width for line. \\
\hline XSTART $=$ & $\#$ & $\begin{array}{l}\text { Data point number interpolated to } \\
\text { column } 1 \text { of matrix (may be non- } \\
\text { integer or negative, default }=0 \text { ). }\end{array}$ \\
\hline DELX $=$ & \# & $\begin{array}{l}\text { Interpolation interval along a matrix row. } \\
\text { The smaller DELX gives the larger } \\
\text { magnification (default }=1.0 \text { ). }\end{array}$ \\
\hline YSTART = & $\#$ & $\begin{array}{l}\text { TV line number interpolated to column } 1 \\
\text { of the matrix (may be negative or non- } \\
\text { integer, default }=0 \text { ). }\end{array}$ \\
\hline DELY $=$ & \# & $\begin{array}{l}\text { Interpolation interval along the columns } \\
\text { (default=0.5). }\end{array}$ \\
\hline NOCS $=$ & $\#$ & $\begin{array}{l}\text { Number of circles to superimpose on } \\
\text { graph, vith center point and radius } \\
\text { to be input (default }=0 \text { ). }\end{array}$ \\
\hline
\end{tabular}




\begin{tabular}{|c|c|c|}
\hline Name & Values & Description \\
\hline INTEG = & $\begin{array}{l}0 \\
1\end{array}$ & $\begin{array}{l}\text { No equivalent radius calculation. } \\
\text { Equivalent radius calculation desired. } \\
\text { Parameters ZINMIN, ZINMAX, INBNN, JLX, } \\
\text { JRX, JTY, JBY, CONVDS also in NAMELIST } \\
\text { if INTEG =1 (default=0). }\end{array}$ \\
\hline IPEN = & $\begin{array}{l}0 \\
1\end{array}$ & $\begin{array}{l}\text { No pinhole transmigsion correction } \\
\text { (default value). } \\
\text { Pinhole tranomission correction with frame } \\
\text { center cs!culated by the above integration } \\
\text { routine. } \\
\text { Pinhole transmission with frame center } \\
\text { as input parameter. }\end{array}$ \\
\hline LEVLOK = & $\begin{array}{l}0 \\
1\end{array}$ & $\begin{array}{l}\text { Plotting levels are input valu's (default value). } \\
\text { Plotting levels used are default values. }\end{array}$ \\
\hline
\end{tabular}

\title{
APPENDIX I-B
}

PARAMETER DEPENDL.NT INPUT

Depending upon the value of the NAMELIST input parametero, additional deta may be required. This card input must be in the following order with the data prepared in the indicated format. The tert below describes the required input in FORTRAN form plus a short functional description. All FORMAT statement numbers are stated as unity for ease of presentation. The following input order refers specifically to TYPE=FUNNGAMES.

\section{READ (5,1) LINFLM \\ 1 FORMAT(I5)}

This variable is the film line number of shot data where the first data above dc zero occurs. Line search of previous data is eliminated.

\author{
IF(NBR.GT.0) READ(5,1) (NBR(I), I=1, NBR) \\ 1 FORMAT(1216)
}

These data are the rowg to be eliminated from the matrix.

IF(ICBKG.EQ.1) READ(5,1) CBKG

1 FORMAT(E12.7)

This variable is subtracted from the final matrix, point by point. 
IF(NORM.GT.0) READ(5,1) ILNOR, IRNOR, ITNOR, IBNOR

1 FORMAT(4I6)

These variables define the left, right, top, and bottom limits of the region of the matrix to search for maximum amplitude during normalization.

\section{READ $(5,1)$ ITHRES \\ 1 FORMAT(I6)}

This input value is the initial guess for the threshold value used by the code in clamping. Its value should be an average of the tip and porch values at region LINFLM.

IF(IBFILE.EQ.0) GO TO 100

READ(5,1) XSTART, DELX, YSTART, DELY

READ(5,2) LIVFLD

READ(5,1) AASLP, BBCON

READ $(5,3)$ TTHRES

1 FORMAT( $(\dot{4} \mathrm{E} 12.7)$

2 FORMAT(I5)

3 FORMAT(I6)

100 CONTINUE

If a background file is to be subtracted, the squaring parameters for the dryrun matrix are entered, as are the line of film where data begins, a multiplicative (AASLP) and additive (BBCON) constant for each dryrun matrix point (usually 1.0 and 0.0 ), and the initial threshold for the dryrun data. These data are input only if IBFILE $\neq 0$.

IF(ITRANS.EQ.0) GO TO 100

READ $(5,1)$ NOTRP

READ(5,2) (XTR(I), Y'TR(I), I=1, NOTRP)

1 FORMAT(I6)

2 FORMAT(2F12.2)

100 CONTINUE

If a transfer function is to be applied to the data, the number of points on the curve is entered on a card, then on a card for each curve point. XTR(I) is the original value; YTR(I) is the transformed value. It is convenient if these data are first normalized so that XTR(INOTRP) = YTR(NOTRP).

IF(NORM.NE.2) GO TO 100

READ $(5,1)$ CMAX

1 FORMAT(F12.0)

100 CONTINUE

Norm $=2$ gives you the option of "overexposure" of a density plot by inputting a maximum amplitude CMAX less than the maximum data value.

IF(LEVLOK.EQ.1) GO TO 100

READ $(5,1)$ ITOP, IBOT, IFRAM, ICOLOR, IEXP, IDOPE, INEG

1 FORMAT $(2 F 6.0,5 \mathrm{I} 6)$

100 CONTINUE 
The LEVLOK=1 parameter allows default plot parameters. If LEVLOK $=0$, read in levels sequentially. If the mode specified in NAMELIST is not CONTOUR, DENSITY, or SPLATTER, set ITOP = 999999. Otherwise, this card determines one ot the levels of exposure for a plot. Repeat this card for each level of exposure desired on a plot. Terminate the input of exposure levels with 99999 as input for ITOP. The input parameter description for the various modez follows.

ITOP. - Contour level, top of densily level, or highest level to be splattered.

IBOT - Bottom of density level or lowest level to be splattered. Contour mode ignores this parameter.

IFRAM - Number of frames to advance film before plotting. Usually this parameter is two for the first level of $\llcorner$ plot, 0 for succeeding levels.

ICOLOR - Color select code for color plots

$=0$ white

$=1$ red

$=2$ green

$=3$ blue

IEXP -4020 exposure level to use

$=0$ heavy exposure (normal)

$=1$ light exposure

DOPE - Point density to use

$=0$ plot every point (fully expose)

$=1$ plot every other point (half-tone)

$=2$ plot every third point, etc.

INEG - Reverses the sense of exposure from positive to negative if INEG $\neq 0$

The next card determines whether to plot the same data in an alternate mode or to continue.

\section{READ(5,1) MODE, LEVLOK}

1 FORMAT(A10, II)

This input allows further plotting of data in a new mode (CONTOUR, DENSITY, OR SPLATTER) and whether to accept default levels or enter new ones. If more plotting is done, this input must be followed by additional exposure level cards if $L E V L O K=0$. If plotting in these three modes is complete, enter ALLbDONEbbl or ALLbDONE, depending on whether default levels are acceptable or not.

IF(NOLNS.EQ.0) GO TO 100

READ(5,1) (X1(I), Y1(I), X2(I), Y2(I), I=1, NOLNS)

1 FORMAT(4F6.0)

100 CONTINUE 
A line plot is generated for each of NOLNS cuts across the matrix. One input card of fuur numbers is required for each cut. The parameter definitions ure

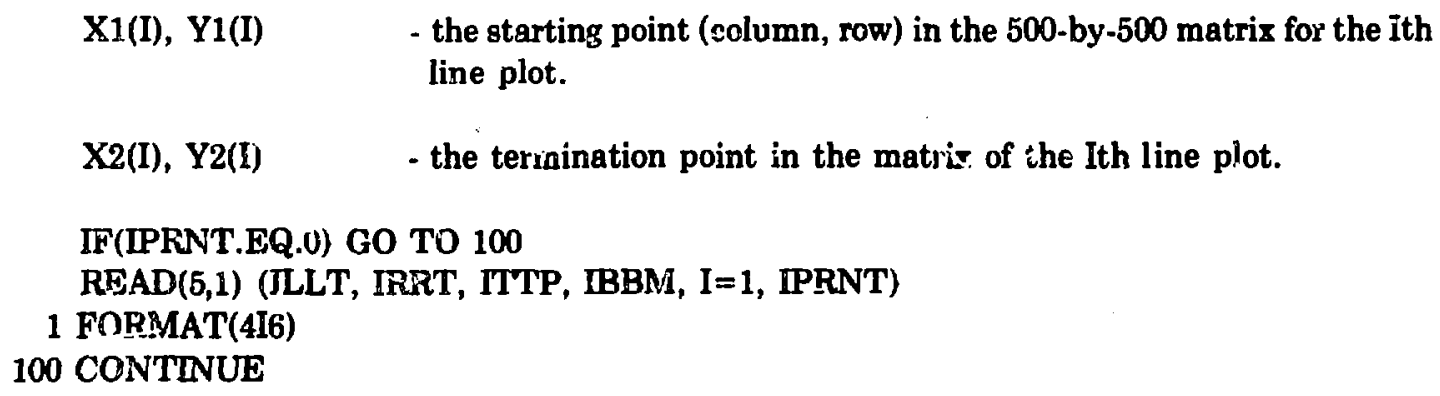

This input defines the rectar gular area of the matrix to be listed on the line printer. The parameter definitions are

$\begin{array}{ll}\text { ILLT } & \text { - lefitmost column } \\ \text { IRRT } & \text { - rightmost column } \\ \text { ITTP } & \text { - topmost row } \\ \text { IBBM } & \text { - bottommost row }\end{array}$

There will be IPRNT of these input cards.

IF(NOCS.EQ.0) GO TO 100

READ(5,1) (XC, YC, RAD, IAVC, I=1, NOCS)

1 FORMAT(3F6.0,I6)

100 CONTINUE

The radial grid lines superimposed on graphs are input by matrix coordinates. There will be one card for each circle to be drawn.

$\mathrm{XC}, \mathrm{YC} \quad-$ the column and row number of the circle center.

RAD - the circle radius in number of matrix points (that is, between 1 and 500).

IAVC - film advance

$=0$ no edvance before plotting

=\# advance \# framer before plotting.

The following input is required if pinhole transmission corrections are required.

IF(IPEN.EQ.0)GO TO 100

IF(IPEN.GE.2)GO TO 99

READ(5,1)RMAX

READ(5,2)NCR, (X(I), Y(I), I=1, NCR)

1 FORMAT(2F6.0) 


\section{FORMAT(I6/(2F6.0))}

GO TO 100

99 READ(5,1)RMAX, CONVDS

$\operatorname{READ}(5,2) \mathrm{NCR},(\mathrm{X}(\mathrm{I}), \mathrm{Y}(\mathrm{I}), \mathrm{I}=1), \mathrm{NCP})$

READ(5,2)IPENN

REAL(5,1)XCEN, YCEN

REPEAT LAST IPENN TIMES

100 CONTINUE

The IPEN parameter determines whether ar not pinhole transmission corrections are to be applied to the final matric. If IPEN $=1$, the code also assumes that INTEG $: 1$ and the $5 \%, 25 \%$, $50 \%$, and $75 \%$ "center of gravity" automatically will be applied consecutively as centers. If $\mathbf{I P E N}=2$, the center of the frame is input manualiy. The definitions are

RMAX - the marimum radius (in $\mathrm{mm}$ ) from the center of the frame for wnich the correction is to be applied,

NCR - the nu $\mathbf{u}_{\text {atber }}$ of input points on the transmission curve,

$\mathrm{X}(\mathrm{I}), \mathrm{Y}(\mathrm{I}) \quad$ - the radius (in $\mathrm{mm}$ ) and transmission (0-1) values,

IPENN - the number of times to manusily input conter coordinates, and

XCEN,YCEN - the center in matrix coordinates, column number, and row number.

If the NAMELIST input is TYPE=ULTRAbDATA, the dryrun data input and transfer cunction input are omitted. The same is true if TYPE=PACKEDTAPE. If TYPE=GMX11bT)ATA or TAPEbDATA, the input is the same as FUNNGAMES. If the input is TYPE=CARDbDATA, input of an established 500-by-500 matrix is through cards, and several options exist in the code, none of which are very attractive. Use of this TYPE is discouraged.

\section{APPENDIX I-C}

\section{SAMPLE INPUT}

The following input assumes that control cards have ataged files of ghot data to FSET1 and files of dryrun data to FSET2 from mass storage. The input will be given, followed by a discussion of output produced.

\section{CARD COLUMN}




$\begin{array}{lllllll}1 & 2 & 3 & 4 & 5 & 6 & 7\end{array}$

$123456789 J 1234567290123456789012345678901234567890123456789012345678901234$

\section{P\$FUNDI}

-TITLE $=60 \mathrm{HANYTITLE}$

- IFILE $=11, \mathrm{IBFILE}=11, \mathrm{MINLIN}=1000, \mathrm{LINTOT}=1500, \mathrm{ITRANS}=1$

-NUM11 $=10, \mathrm{NUM} 31=40, \mathrm{NUM} 31=10, \mathrm{NUM} 41=40, \mathrm{NUM} 42=160, \mathrm{NUM} 43=400, \mathrm{NUM} 44=600$

$-\mathrm{SS}(1)=-0.03125,0.0,0.28125,0.5$,

-XS'TART $=0.0, \mathrm{DELX}=2.10, \mathrm{YSTAR} T=0.0, \mathrm{DEL} Y=0.5$,

-LEVLOK $=1, \mathbb{P E N}=1$,

$-\mathrm{INTER}=1, \mathrm{ZINMIN}=40.0, \mathrm{ZINMAX}=100.0, \mathrm{INBNN}=12, \mathrm{JLX}=175_{,} \mathrm{JP} \mathrm{F}_{*}=425, \mathrm{JTY}=80, \mathrm{JBY}=325$, - CONVDS $=0.06451 \$$

$--17$

---150---350---150---350

$-.-700$

0.0

$---16$

1.0

$-.-650$

$-\cdots \cdot-\cdot 4$

$0.0-\cdots-0.0$

$14.7-\cdots-\ldots .2$

$115.0 \ldots . . . .97 .3$

$342.0 \ldots \ldots-. .-416.1$

SPLATTER--1

ALL-DONE--1

56.:

-...-5

$0.0--1.0$

4.05--0.995

12.15-01963

20.25-0.912

36.45-0.791

$\$ F M$

The above input caunen default to MODE-DENSITY, TYPE - FUNNCAMES and DERIV = blenk. The ahot data are on fle 11 of ESET1 and dryrun data on filo 11 of FSETZ. The cedo will accept line longths (number of pointe in line pilis HST) between 1000 and 1500 points as valid. A transfer function will bo ingut, the plot levels will be dofault values, equivalont radius calculation will bo performed, and pinhole correctiona with contors of gravity calculated by the oquivalent radlus routine will be mode. DELX and DELY values are ehonen Initialiy no that MINLIN/DELX $=600$ and TV line/DBL $Y=\$ 00$.

The formatted data input carda are: fllm line number of fiat thot HGT; normalieation range; shot throshold: equaring paramotorn for dryrun data; flim line number of flnt dryrun HST; dryrin multiplicative and additive numbern; drytun threahola; number of polnte in tranufis curvo; four tranufor curve polnts; furthor plot command with dofault plot lovoly; ond of plotting of date frame; maximum radius for pinhole corrections; flve points on plnhole correction curve;. and date points for pinhole correction curve. 
The program will clamp the shot frame, normalize, and plct in the density mede using default levels; clamp the dryrun frame, normalize and plot in the density mode using default levels; subtract the dryrun from the shot frame, apply the transfer function to the difference, then normalize and plot in the density mode using default levals. The corrected frame will then be plotted in the splatter mode using defailt levels for that inode. Equivalent radius calculations will then be performed in 12 intervals of $5 \%$, with numerical results printed. The radius of the 1st, 4th, 9th, and 12th intervals will then be sequentially applied as centers for pintuis calculations, with corrected frames for each radius plotted automatically in the density mode. 


\section{PART II}

\section{DARN, A CODE FOR THE REDUCTION OF DIGITAI PINEX RUN DATA WITH EMP SHIFTS}

\section{INTRODUCTION}

The format and processing procedures of digitally recorded pinex data of NTS experiments are described in Part $I$ of this report. The processing code, DENBIG, gives very good results from normal input data. However, the environment of the. cameras and signal cables may induce [by electromagnetic pulse (EMP)] momentary amplitude shifts in transmitted data, as well as squelching the important sync tip signals. The latter signals are necessary for line end point determination in normal processing.

Code DARN attempts to eliminate the above two problems by depending on real background and sync tip positions in run and dryrun data being consistent.

\section{LINE CLAMPING}

Tests on several data sets have demonstrated that dryrun and run data are highly consistent with respect to timing once data transmission has started. Figures 11 and 12 show the data in the region of the first horizontal sync tip (HST) from the dryrun and run, respectively. The initial shift in positions of the leading edges is 192 data points or $9.6 \mu \mathrm{s}$ in the initial timing sequences. However, as subsequent points are inspected in the data sets, HST positions maintain this constant displacement. Figures 13 and 14 demonstrate the constancy at a position more than 100000 points later in the data sets.

One can thus infer HST positions in run data by determining HST positions in dryrun data and the initial displacement of the first run and first dryrun HST. This procedure allows run litıts to be clamped when the HST has been clobbered.

The code uses FSET1 and FSET2 as run and dryrun input files, respectively. The data from FSET2 is searched until the beginning and ending foint of the first HST is determined. The first HST of the run data is then found and the displacement

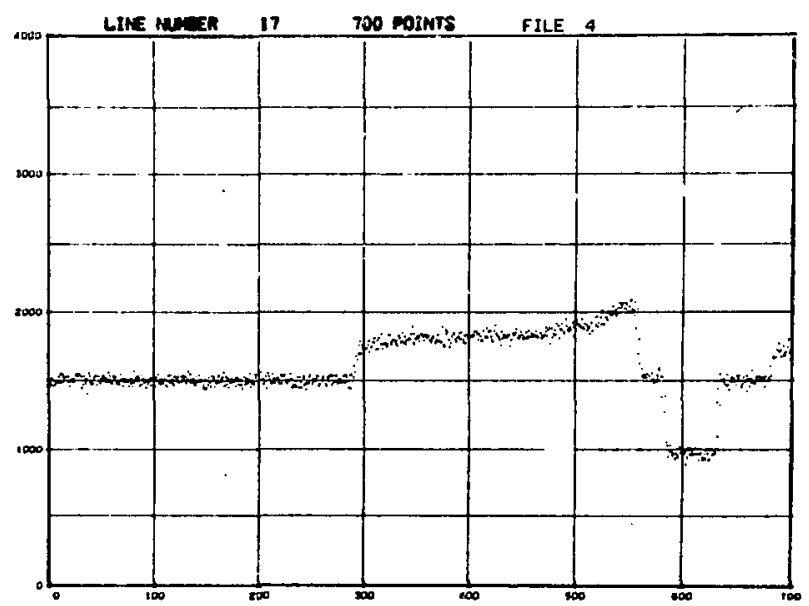

Fig. 11.

The dryrun data segment that contains the first HST, which begins at point number $16 X$ $700+584=11784$.

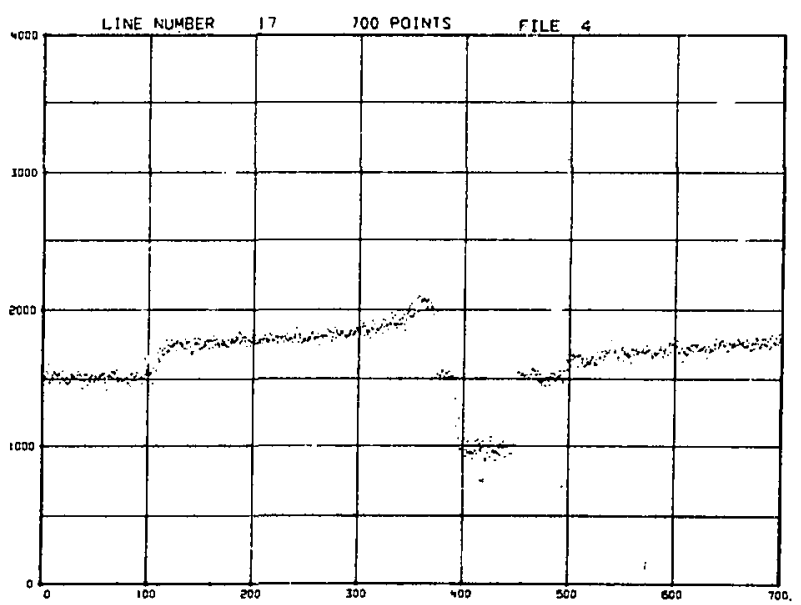

Fig. 12.

The run data segment that contains the first $H S T$, whirh begins at point number $16 \times 700$ $+392=11592$. 


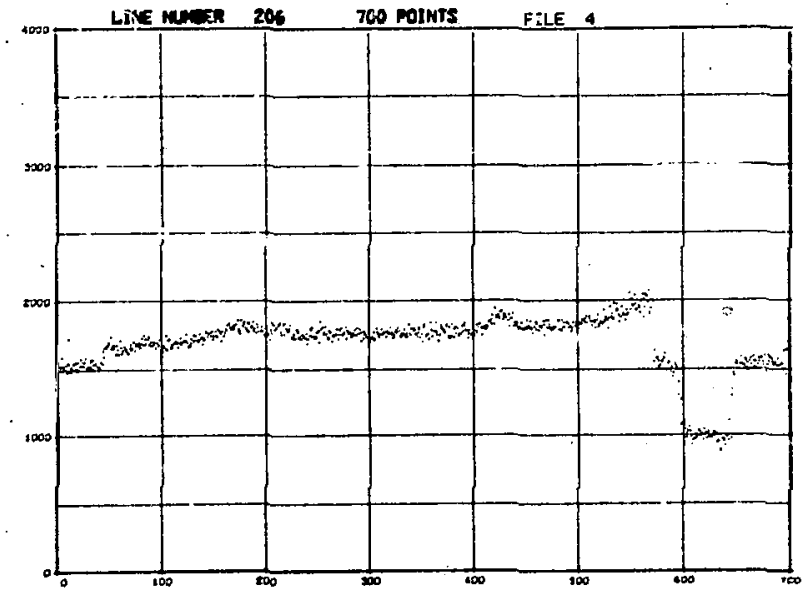

Fig. 13.

The dryrun duta segment that contains the HST at the end of TV line \#219, beginning at point $\# 205 \times 700+596=144096$.

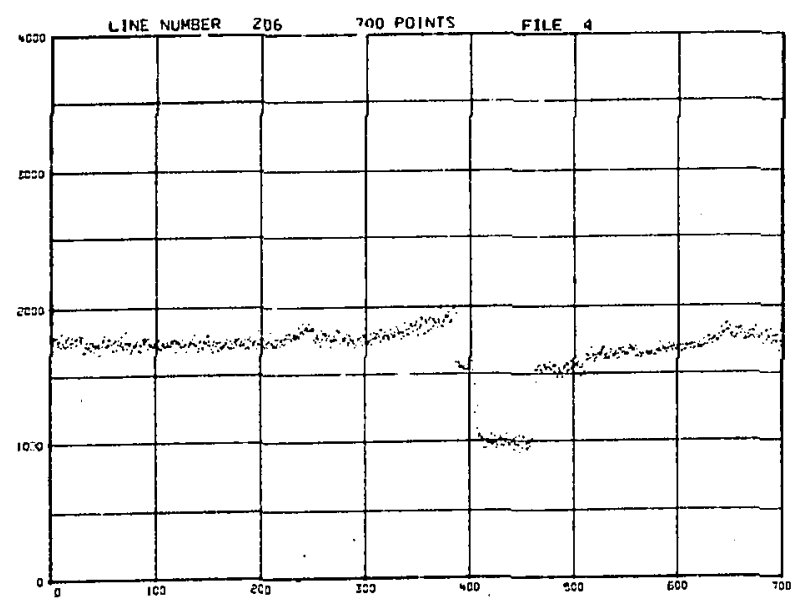

Fig. 14.

The run data segment that contains the HST at the end of TV line \#219, beginning at point \#205 X 700 + 404 = 143904. The displacement remains at 192 points.

determined. A line of dryrun data is then determined by taking all points from the end of the first dryruri HST to the beginning of the second. The number of data points in this line, the displacement of the first point from leading edge of the HST' (XSLIM) and the data points themselves are written on FSET14. The same number of points are then written from the run data set, FSET1, onto
FSET13, along with the XSLIM value determined from the dryrun. The second dryirun HST is then determined, and that number of points skipped over in run data. Successive lines and HrTs are generated by looping through the above procedure. Care is taken to keep data alignment from FSET1 and FSET2 with the proper displacement determined from HST No. 1. Porch and threshold values described in the operation of DENBIG are determined from dryrun data only and are applied to both run and dryrun lines when appropriate.

\section{AMPLITUDE CORRECTINNS}

Figures 15 and 16 are equivalent sections of run and drurun data where a constant shift in amplitude of the run data was induced by an EMP. As is evident from Figs. 13 and 14, the true background of the run data should be only a small shift from the dryrun data. The code attempts to remove the EMP shift by integrating over equal areas near the ends of run and dryrun lines and by subtracting the average difference from the run line. Therefore, shift corrections are included on a line-by-line basis, each line of data being compared to its equivalent dryrun line amplitude.

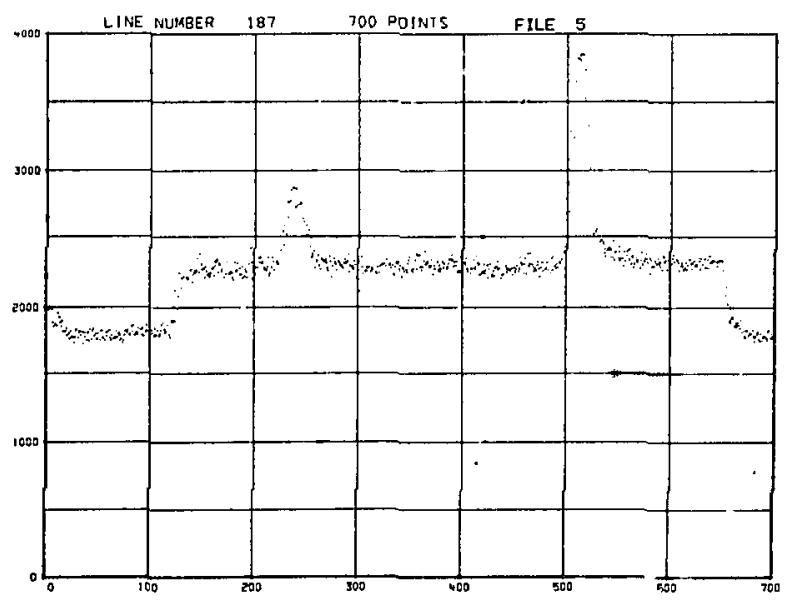

Fig. 15.

A segment of run lata that contains an EMP shift. The data on the left and right extremities are dc zero or porch levels. The HSTs are missing. The porch-to-pedestal displacement is also too large. 


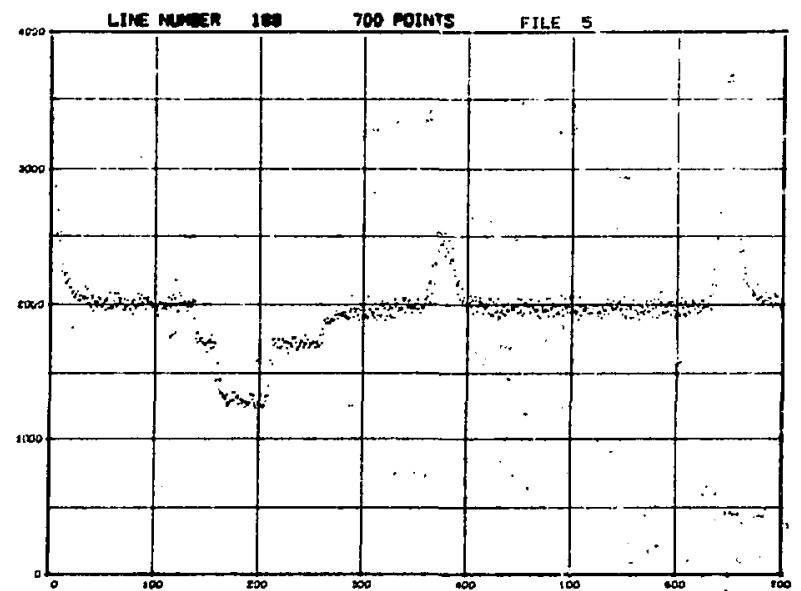

Fig. 16.

$A$ segment of the dryrun data showing the same TV line as the run data of Fig. 5. The EMP shift in the data of Fig. 5 is removed by subtracting the difference in pedestal values of the two data sets irom the run data.

Figure 17 is a photograph of a frame of data on a TV monitcr that demonstrates the presence of shifts in the incoming data in three regions of the frame. The digitized data lacked many sync tips, preventing analysis by code DENBIG without timeconsuming, hand-performed, data corrections. Figure 18 is a density plot of the frame output by DARN with an inadequate shift correction, but demonstrating the ability to clamp lines without sync tips. Figure 19 is a density plot output by DARN with sync tip, threshold, and background levels all tied to dryrun data. This figure is a striking example of how important good dryrun data can be to subsequent run analysis. Good corrections cannot be made, however, in those cases where EMP shifts are so large that saturation of the 12-bit digitizer occurs.

\section{PROGRAM OUTPUT}

Code DARN requires more storage to handle run and dryrun files simultaneously than does its predecessor DENBIG. Storage limitations require that some of the options of DENBIG be omitted, particularly pinhole corrections, equivalent radius

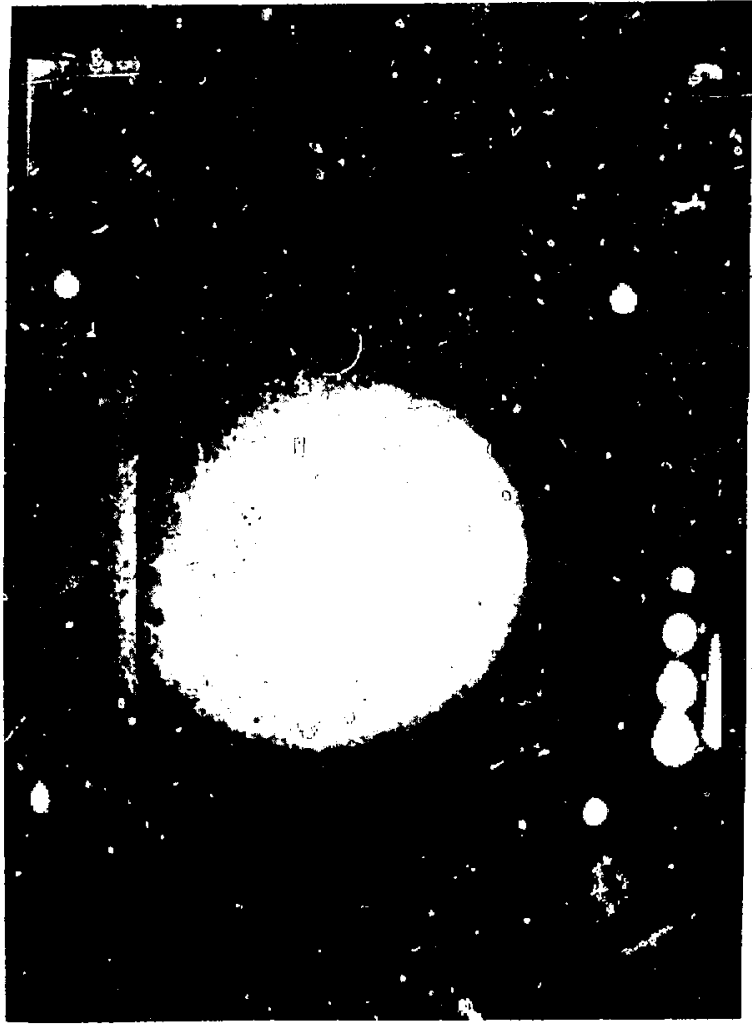

Fig. 17.

A TV monitor photograph of the data presented in Figs. 8 and 9.

calculations, and plots of line cuts. However, code DARN does take the clamped lines of both the run and dryrun, interpolates each frame into a 500-by500 array, and applies transfer function corrections and subtraction of dryrun frame from run frame. The density, contour, and splatter plot routines are available for each frame.

Limitations on calculations by DARN require an understanding of internal data represeniation. FSET13 contains the clamped line data of the run, corrected for EMP shifts, whereas FSET14 contains the clamped line data of the dryrun. These files can be saved for subsequent interpolation and processing by DENBIG. Alternatively, FSET18 contains the interpolated 500-by-500 array of run data, corrected by applying an input transfer function, whereas FSET19 contains the dryrun frame. These files can also be saved for further processing. 


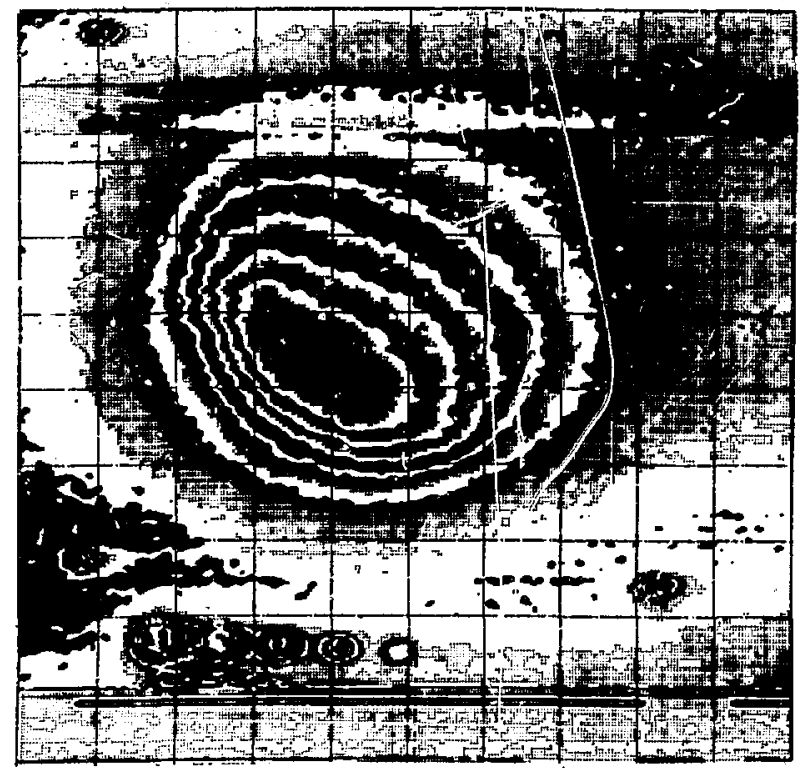

Fig. 18.

A density plot of the rin data of Fig. 7 with inadequate removal of EMP shift level.

\section{CONCLUSIONS}

The importance of ensuring good dryrun data under identical conditions to the run cannot be overemphasized. When run data contains no shifts, the dryrun : an be used effectively to subtract irregularities in camera response as a function of position across the line, as wall as to establish a transfer function without background effects. When shifts do occur, the results presented in this report

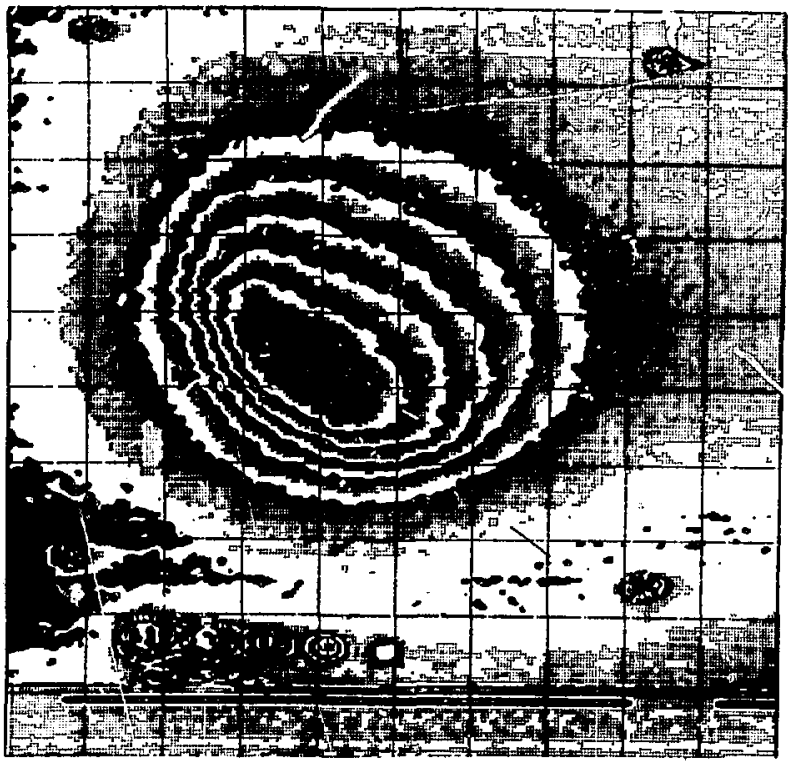

Fig. 19.

A density plot of the run data of Fig. 7 with all data referred to dryrun data, effectively removing EMP shifts.

demonstrate that accurate data can be extracted without any direct alterations of the data. Code DARN accurately determines nonsaturated shift levels and properly positions symc tips by referencing all rur data to dryrun data. When shifts are so large as to cause saturation, most probably the sync tips will be missing. Code DARN can at least establish the data frame, enaibling extraction of that part of the data frame that has nonsaturated values.

\section{APPENDIX II-A}

\section{INPUT PARAMETERS}

The input to DARN is very similar to that of DENBIG, except the options INTEG, IPEN, NOLNS, and NOCS are inoperative, whereas others have only a single applicable function.

These are TYPE = FUNNGAiviES, TIPP = blank, and DERIV = blank.

The following input description assumes a familiarity with DENBIG input. 
Card 1: READ(5,FUNDI)

This is the NAMELIST group, except as noted above, described in DENBIG.

Card 2: READ(5,1)LINSHOT

1 FORMAT(I5)

This is the film line number where the first valid HST of the run occurs.

Card 3: READ(5,1)LINDRY

1 FORMAT(I5)

This is the film line number where the first valid HST of the dryrun occurs.

Card 4: IF(ICBKG.EQ.0)GOTO 100

READ (5,2)CBKG

2 FORMAT(E12.7)

100 CONTINUE

This parameter allows a constant value to be subtracted from the final run frame.

Card 5: IF(NORIV.E6.0)GO TO 100

READ(5,3)ILNOR, IRNOR, ITNOR, IBNOR

3 FORMAT(4IF)

100 CONTINUF.

These values a:e the left and right column limits and top and bottom row limits of the final frame to search for maximum amplitude of output plots.

Card 6: READ $(5,3)$ ITHRES

3 FORMAT (4I6)

This value is the initial threshold for HST search in the run data. It should be an average of the first tip and porch values.

Card 7: IiEAD(5,DARNIN)

MOD1 $=$ 10HDARNbbbbbb

IFLDR = file \# of dryrun àata.

ITHDR $=$ threshold of dryrun data.

SHIFT = difference in amplitude between shot and dryrun pedestal.

TOL = decimal fraction of SHIFT which can be tolerated in pedestal comparison without correction for IMP. A value of 0.05 is suggested.

NOWPLT $=1$ for plots of each frame produced.

$=0$ for plot of final subtracted frame only.

The above NAMELIST input file initializes dryrun and pe $\dot{q}$ stal parameters.

Card 8: IF(ITRANS.EQ.0)GO TO 100

READ(5,1)NOTRP, (XTR(I), YTR(I), I=1, NOTRP)

1 FORMAT(I6, (2F12.0))

100 CONTINUE

The number of points on the trangfer curve and point values are entered on successive cards if a transfer function correction is included. 
Card 9: IF(NORM.NE.2)GO TO 100

READ(5,1)CMAY

1. FORMAT'F 12.0)

100 CON1TNUE

The maximum amplitude of output plots is entered here if the "overexposure" feature is desired.

Card 10: If (NOWPLT.NE.1)GO TO $10 \mathrm{~J}$

READ(5,1)TTOP, IBOT, IFRAM, COL, IEXP, IDOPE

1 FORMAT(2F6.0, I6, F6.0, 4I6)

IF((ITOP.GE.999998)GO TO 99

,

1

1

100 CONTINUE

99 READ $(5,2)$ MODE

2 FORMAT(A10)

This sequence of input is the plot level input described in DENBIG. This deck is used to plot the shot data only, before dryrun subtraction. The MODE must be SHOTbONLY.

Card 11: READ(5,1)XSTART, DELX, YSTART, DELY

1 FORMAT(4E12.0)

This input is the squaring parameter for the dryrun frame.

Card 12: READ(5,1)AA, BD

1 FORMAT(2E12.7)

These values are slope and zero shift parameters to be applied to background before subtraction. Normal values are 1.0 and $\mathbf{0 . 0}$.

Card 13: IF(NORM.NE.2) GO TO 100

READ(5,1)CMAX

1 FORMAT(F12.0)

100 CONTINUE

If "overexpcsure" of the background plot is desired, the maximum amplitude is entered here.

Card 14: IF(NOWPLT.NE.1)GO TO 100

READ(5,1)ITOP, IBOT; IFRAM, COL, IEXP, IDOPE

1 FORMAT(2F6.0, I6, F6.0, 4I6)

IF(ITOP.GT.999998)GO TO 99

,

,

100 CONTINUE

99 READ $(5,2) M O D E$

2 FORMAT(A10)

The plotting intervals for the dryrun frame are entered next and end with MODE card DRYRUNONLY. 
Card 15: 10 READ(5,1)ITOP, IBOT, IFRAM, COL, IEXP, IDOPE IF(ITOP.GT.999998) GO TO 100

$$
\begin{aligned}
& \text { GO TO } 10 \\
& \operatorname{READ}(5,2) \\
&
\end{aligned}
$$

$100 \operatorname{READ}(5,2) \mathrm{MODE}$

,

The plotting intervals for the final difference frame are entered next followed by an input MODE. If no further plots are desired, MODE is ALLbDONE. Alternatively, one of the other modes can be entered, followed by further plotting interval input. 